\section{(6) OPEN ACCESS}

- Additional material is published online only. To view please visit the journal online (http://dx.doi.org/10.1136/ thoraxjnl-2013-204198)

For numbered affiliations see end of article.

\section{Correspondence to} Dr Sam M Janes, Lungs for Living Research Centre,

UCL Respiratory, University College London, London,

WC1E 6JF, UK;

s.janes@ucl.ac.uk

Received 17 July 2013 Revised 9 January 2014 Accepted 24 January 2014 Published Online First 18 February 2014

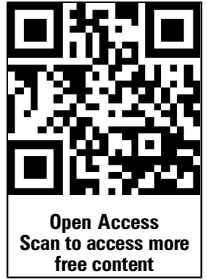

CrossMark

To cite: Pipinikas $C P$, Kiropoulos TS, Teixeira VH, et al. Thorax 2014;69: 548-557.

\title{
Cell migration leads to spatially distinct but clonally related airway cancer precursors
}

\author{
Christodoulos P Pipinikas, ${ }^{1}$ Theodoros S Kiropoulos, ${ }^{1,2}$ Vitor H Teixeira, ${ }^{1}$ \\ James M Brown, ${ }^{1}$ Aikaterini Varanou, ${ }^{1}$ Mary Falzon, ${ }^{3}$ Arrigo Capitanio, ${ }^{3}$ \\ Steven E Bottoms, ${ }^{1}$ Bernadette Carroll, ${ }^{4}$ Neal Navani, ${ }^{1,4}$ Frank McCaughan, 5,6 \\ Jeremy P George, ${ }^{4}$ Adam Giangreco, ${ }^{1}$ Nicholas A Wright, ${ }^{7,8}$ Stuart A C McDonald, 7,8 \\ Trevor A Graham, ${ }^{7,9}$ Sam M Janes ${ }^{1}$
}

\section{ABSTRACT}

Background Squamous cell carcinoma of the lung is a common cancer with $95 \%$ mortality at 5 years. These cancers arise from preinvasive lesions, which have a natural history of development progressing through increasing severity of dysplasia to carcinoma in situ (CIS), and in some cases, ending in transformation to invasive carcinoma. Synchronous preinvasive lesions identified at autopsy have been previously shown to be clonally related.

Methods Using autofluorescence bronchoscopy that allows visual observation of preinvasive lesions within the upper airways, together with molecular profiling of biopsies using gene sequencing and loss-of-heterozygosity analysis from both preinvasive lesions and from intervening normal tissue, we have monitored individual lesions longitudinally and documented their visual, histological and molecular relationship.

Results We demonstrate that rather than forming a contiguous field of abnormal tissue, clonal CIS lesions can develop at multiple anatomically discrete sites over time. Further, we demonstrate that patients with CIS in the trachea have invariably had previous lesions that have migrated proximally, and in one case, into the other lung over a period of 12 years.

Conclusions Molecular information from these unique biopsies provides for the first time evidence that field cancerisation of the upper airways can occur through cell migration rather than via local contiguous cellular expansion as previously thought. Our findings urge a clinical strategy of ablating high-grade premalignant airway lesions with subsequent attentive surveillance for recurrence in the bronchial tree.

\section{INTRODUCTION}

The proposed progression model for squamous cell carcinoma $(\mathrm{SqCC})$ of the lung is a stepwise change in morphology from the early, non-specific change of squamous metaplasia to mild, moderate and severe dysplasia (SD) to carcinoma in situ (CIS) and finally invasive cancer. ${ }^{1}$ Although preinvasive lesions such as SD and CIS are thought to be precursors of invasive $\mathrm{SqCC}$, not all progress to malignant tumours. ${ }^{1}$ We have previously documented that a minority of high-grade lesions progress to invasive carcinoma within 2 years of follow-up with the majority remaining static or regressing. ${ }^{2}$ Importantly, the presence of these preinvasive

\section{Key messages}

What is the key question?

- Are spatially distinct precancerous lesions of the airways related?

\section{What is the bottom line?}

- We demonstrate that cells from carcinoma in situ lesions are capable of migrating across histologically normal epithelium and establishing new clonal lesions and hence propose a novel mechanism of 'field cancerisation' within human airways with important implications for lung cancer clinicians.

\section{Why read on?}

- Using longitudinal tracking of lesions, our study provides a novel answer to arguments that have run since the publication of the Franklin paper (1997), which noted an identical mutation in separate premalignant lesions leading to speculation that either the mutation occurred across the whole bronchial tree or that identical mutations were occurring independently generating new clones.

lesions predisposes to cancer development at remote sites. ${ }^{2} 3$

An increasing body of evidence suggests that genetic mutations accumulate at a preneoplastic stage, long before clinical or histological detection. ${ }^{4}$ Clonal expansion of these mutants may not cause morphological change but can predispose the epithelium to subsequent tumour development, ${ }^{5}$ a process known as 'field cancerisation'. Field cancerisation demonstrated in several organs ${ }^{6-12}$ was first proposed by Slaughter et al. ${ }^{13}$ They observed oral cancers to grow multifocally at sites surrounded by areas of abnormal, precancerous cells and proposed the regional preconditioning of epithelium by an unknown carcinogenic insult. ${ }^{13}$ Braakhuis et $a l^{14}$ subsequently suggested the precancerous field was monoclonal in origin, a definition that fits well with the observation of several preinvasive lesions 
carrying the same rare somatic TP53 mutation in the bronchial tree of a patient at autopsy. ${ }^{15}$

Previous studies investigating the accumulation of somatic changes in preinvasive and invasive lesions used specimens taken at a single time point, often from surgical resection specimens. ${ }^{16-18}$ The development of autofluorescence bronchoscopy (AFB) has improved detection of preinvasive lesions in the lung, ${ }^{19}$ providing the means for the longitudinal tracing and facilitating the anatomical and biological study of the natural history of preinvasive lesions in situ. We developed our longitudinal study of preinvasive lesions to help delineate both their clonal and temporal relationship.

In our study, we wished to answer whether these lesions occur in a field of clonally related epithelium, whether lesions with identical mutations occur independently or whether they occur after migration through a genetically unrelated epithelium and then expand in a new favourable environment or 'niche' at a distant location. We combine temporal mapping of preinvasive lung lesions using AFB with mutation analysis of biopsy samples to measure the clonal expansion of these lesions within the tracheobronchial tree and delineate the extent and mechanism of 'field cancerisation'. We focus on individuals with rare tracheal CIS disease and examine their clonal and temporal relationship with other preinvasive lesions. The first patient described gives a unique insight into the mechanism of preinvasive epithelial cell migration and subsequent clonal expansion over a 12-year period, the additional four patients further demonstrate that the occurrence of tracheal CIS is usually preceded by clonally related but spatially distinct lesions more distal in the airway.

\section{METHODS}

\section{Patient recruitment}

The University College London Hospitals (UCLH) Early Lung Cancer Surveillance Program uses AFB to assess patients at high risk for lung cancer. Eligibility criteria for inclusion into the programme involve the detection of one or more preinvasive lesions in the absence of clinically or radiologically detected invasive carcinoma or development of preinvasive lesions at remote sites from the site receiving curative treatment for carcinoma. All patients in the programme are investigated with repeated $\mathrm{AFB}$ and $\mathrm{CT}$ or positron emission tomography/CT . Full details of the surveillance protocol have been previously described. ${ }^{20}$ Sequential AFB procedures allow the collection of biopsies from both the same preinvasive lesion longitudinally and the detection and biopsy of new lesions either de novo or via spread from an initial lesion. Each lesion is biopsied by separate forceps to eliminate cross-contamination. Full informed consent was obtained from all patients.

\section{Tissue sectioning and laser capture microdissection}

Approximately 10 serial sections of $8 \mu \mathrm{m}$ thickness were cut from each formalin-fixed, paraffin embedded block. The first and last sections were stained with haematoxylin and eosin using a standard protocol and reviewed by two independent histopathologists to identify areas of histologically abnormal epithelium. Normal or preinvasive areas of the epithelium were then microdissected separately from methyl green-stained sections (Vector Laboratories, USA) using the PALM Microbeam system (Zeiss, Germany). Genomic DNA was extracted from the captured cells by digestion in PicoPure proteinase-K buffer (Arcturus, UK) according to the manufacturer's instructions. Tubes containing digestion buffer but no captured material were included in each DNA extraction batch and served as negative controls.

\section{Mutational detection}

DNA from the invasive cancer or most recent CIS lesion was used to screen for somatic mutation(s) in TP53 (exons 5-8), $K-R A S$ (exon 1, codons 12-13) and CDKN2A (p16 ${ }^{\mathrm{INK} 4 \mathrm{a}}$, exon 2) using nested-PCR. Preinvasive lesions collected longitudinally from each patient were then examined at those genomic loci mutated in the corresponding screening specimen. Constitutional DNA from whole blood was also examined in order to exclude the possibility of the detected genetic abnormality being a germline mutation. The obtained sequence electropherograms were compared with the published reference sequences using the basic local alignment search tool (BLAST). To determine the assay sensitivity and the percentage of TP53 mutant cells that need to be present to allow detection of a mutation, we serially diluted tumour DNA carrying the TP53 deletion with normal, wildtype control DNA. The sensitivity of the PCR-based detection method was determined to be $\leq 5 \%$. PCR primer/product size details and amplification reactions are

Table 1 Demographic and clinical characteristics of the patients with tracheal carcinoma in situ included in the study

\begin{tabular}{|c|c|c|c|c|c|c|c|c|}
\hline Patient & Sex & $\begin{array}{l}\text { Smoking (pack } \\
\text { years) }\end{array}$ & $\begin{array}{l}\text { Initial malignancy } \\
\text { (stage)* }\end{array}$ & Site & $\begin{array}{l}\text { Age } \\
\text { (surgery) }\end{array}$ & $\begin{array}{l}\text { Site(s) of new tumour (histology/time to } \\
\text { diagnosist) }\end{array}$ & $\begin{array}{l}\text { Sites } \\
\text { tested }\end{array}$ & $\begin{array}{l}\text { Specimens } \\
\text { analysed }\end{array}$ \\
\hline 1 & $M$ & 60 & SqCC (T1NOM0) & LUL & 58 & $\begin{array}{l}\text { Left completion pneumonectomy }(\mathrm{SqCC}) \text { arising } \\
\text { from a region of LUL stump }\left(\mathrm{M}_{93}\right)\end{array}$ & 19 & 46 \\
\hline 2 & M & $30-40$ & SqCC (T1NOM0) & LLL & 72 & $\begin{array}{l}\text { LLL stump }\left(\mathrm{SqCC} / \mathrm{M}_{48}\right) \\
\text { Right Lung }\left(\mathrm{SqCC} / \mathrm{M}_{50}\right) \\
\left.\text { LUL (CIS } / \mathrm{M}_{78}\right) \\
\text { Trachea }\left(\mathrm{SD} / \mathrm{M}_{85}\right)\end{array}$ & 6 & 8 \\
\hline 3 & M & 47 & SqCC (T1NOM0) & LUL & 66 & $\begin{array}{l}\text { Lower Trachea/LMB stump (both early invasive } \\
\mathrm{Sq}\left(\mathrm{C} / \mathrm{M}_{42} \text { ) }\right.\end{array}$ & 5 & 6 \\
\hline 4 & M & 40 & SqCC (T2NOM0) & RUL & 57 & $\begin{array}{l}\text { RUL stump }\left(\mathrm{SqCC} / \mathrm{M}_{11}\right) \\
\text { Trachea posterior wall } \\
\left.\text { (invasive } \mathrm{SqCC} / \mathrm{M}_{11}\right)\end{array}$ & 3 & 3 \\
\hline 5 & M & 40 & SqCC (T1N0) & $\begin{array}{l}\text { RML } \\
\text { RLL }\end{array}$ & 70 & $\operatorname{RIB}\left(\mathrm{CIS} / \mathrm{M}_{60}\right)$ & 6 & 7 \\
\hline
\end{tabular}

${ }^{*}$ Refers to initial malignancy detected prior to patient's referral to UCLH.

tRefers to the time interval between surgery and diagnosis of new SqCC/CIS.

CIS, carcinoma in situ; LLL, left lower lobe; LMB, left main bronchus; LUL, left upper lobe; RIB, right intermediate bronchus; RLL, right lower lobe; RML, right middle lobe;

RUL, right upper lobe; SqCC, squamous cell carcinoma; SD, severe dysplasia; UCLH, University College London Hospital. 
provided in the online data supplement (see online supplementary tables S1 and S2, respectively).

\section{Mutation verification}

The Catalogue of Somatic Mutations in Cancer database (http://www.sanger.ac.uk/genetics/CGP/cosmic; Cambridge, UK) was used to verify all the somatic mutations identified. Nucleotide changes in the electropherogram were considered as true somatic mutations only when seen in the absence of any background noise/artefact and were accepted only if confirmed by repeating the PCR from the original DNA lysate.
Loss of heterozygosity ( $\mathrm{LOH})$

Constitutional blood DNA from patient 1 was amplified for three microsatellite markers (D17S 1506, D17S 1678 and D17S 1881) using Qiagen's Multiplex PCR kit (Crawley, UK) according to manufacturer's instructions and $5^{\prime}$-tagged primers with either HEX or FAM fluorescent probes. Preinvasive and control samples with sufficient DNA were subsequently analysed for $\mathrm{LoH}$ using only microsatellites found to be heterozygous in constitutional DNA. Fragment analysis was carried out on an ABI 3100, and data were analysed using PeakScanner V.1.0 (Applied Biosystems). $\mathrm{LoH}$ was calculated using the height ratio of the

Table 2 Tracing the spread of the TP53 p.E294fs*51 (c.880delG) mutant clone over time in patient 1

\begin{tabular}{|c|c|c|c|c|c|c|}
\hline $\begin{array}{l}\text { AFB } \\
\text { date }\end{array}$ & Month & Biopsy site & Diagnosis & AFB status & TP53 status & LoH/RoH (D17S 1881) \\
\hline $10 / 2000$ & $M_{38}$ & $\begin{array}{l}\text { LUL stump } \\
\text { LLL orifice (control) } \\
\text { LLL (control) } \\
{ }^{*} \mathrm{MC} \text { (control) } \\
\text { RUL (control) } \\
\text { RLL (control) }\end{array}$ & $\begin{array}{l}\text { CIS } \\
\text { NAD } \\
\text { NAD } \\
\text { NAD } \\
\text { NAD } \\
\text { NAD }\end{array}$ & $\begin{array}{l}+ \\
- \\
- \\
- \\
-\end{array}$ & $\begin{array}{l}\text { Mutant } \\
\text { Wildtype } \\
\text { Wildtype } \\
\text { Wildtype } \\
\text { Wildtype } \\
\text { Wildtype }\end{array}$ & $\begin{array}{l}\mathrm{LoH} \\
\mathrm{RoH} \\
\mathrm{RoH} \\
\mathrm{RoH} / \mathrm{RoH} \\
\mathrm{RoH} \\
\mathrm{RoH}\end{array}$ \\
\hline $03 / 2001$ & $\mathrm{M}_{43}$ & LUL stump & SD & + & Mutant & $\mathrm{LoH}$ \\
\hline $07 / 2001$ & $M_{47}$ & LUL stump & $\mathrm{CIS}$ & + & Mutant & $\mathrm{LoH}$ \\
\hline $12 / 2001$ & $M_{51}$ & LLL (control) & NAD & - & Wildtype & $\mathrm{RoH}$ \\
\hline $01 / 2003$ & $M_{64}$ & Left main bronchus & SD & + & Mutant & $\mathrm{N} / \mathrm{A}$ \\
\hline $07 / 2003$ & $M_{70}$ & $\begin{array}{l}\text { LLL (control) } \\
\text { tLLL orifice } \\
\text { Proximal left main bronchus } \\
\text { Left main bronchus }\end{array}$ & $\begin{array}{l}\text { NAD } \\
\text { SD } \\
\text { SD } \\
\text { CIS }\end{array}$ & $\begin{array}{l}- \\
+ \\
+ \\
+\end{array}$ & $\begin{array}{l}\text { Wildtype } \\
\text { Mutant } \\
\text { Mutant } \\
\text { Mutant }\end{array}$ & $\begin{array}{l}\text { RoH } \\
\mathrm{LoH} / \mathrm{LoH} \\
\mathrm{LoH} \\
\text { N/A }\end{array}$ \\
\hline $11 / 2003$ & $M_{74}$ & $\begin{array}{l}\text { LLL (control) } \\
\text { Proximal left main bronchus }\end{array}$ & $\begin{array}{l}\text { NAD } \\
\text { CIS }\end{array}$ & $\overline{+}$ & $\begin{array}{l}\text { Wildtype } \\
\text { Mutant }\end{array}$ & $\begin{array}{l}N / A \\
N / A\end{array}$ \\
\hline $05 / 2004$ & $M_{80}$ & LLL (control) & NAD & - & Wildtype & $\mathrm{N} / \mathrm{A}$ \\
\hline $09 / 2004$ & $M_{84}$ & LLL (control) & NAD & - & Wildtype & $\mathrm{N} / \mathrm{A}$ \\
\hline $04 / 2006$ & $\mathrm{M}_{104}$ & $\begin{array}{l}\mathrm{MC} \\
\mathrm{MC} \text { (control) }\end{array}$ & $\begin{array}{l}\text { CIS } \\
\text { NAD }\end{array}$ & $\begin{array}{l}+ \\
-\end{array}$ & $\begin{array}{l}\text { Mutant } \\
\text { Wildtype }\end{array}$ & $\begin{array}{l}N / A \\
N / A\end{array}$ \\
\hline $08 / 2006$ & $\mathrm{M}_{108}$ & Lower anterior trachea & $\mathrm{CIS}$ & + & Mutant & $\mathrm{LoH}$ \\
\hline $01 / 2007$ & $\mathrm{M}_{113}$ & Lower lateral trachea & CIS & + & Mutant & LoH \\
\hline $04 / 2007$ & $\mathrm{M}_{116}$ & Lower trachea & CIS & + & Mutant & $\mathrm{N} / \mathrm{A}$ \\
\hline $03 / 2008$ & $\mathrm{M}_{127}$ & $\begin{array}{l}\text { RMB (control) } \\
\text { RMB } \\
\text { Lower trachea (control) }\end{array}$ & $\begin{array}{l}\text { NAD } \\
\text { MoD } \\
\text { NAD }\end{array}$ & $\begin{array}{l}- \\
+ \\
-\end{array}$ & $\begin{array}{l}\text { Wildtype } \\
\text { Mutant } \\
\text { Wildtype }\end{array}$ & $\begin{array}{l}\text { N/A } \\
\text { N/A } \\
\text { RoH }\end{array}$ \\
\hline $08 / 2008$ & $\mathrm{M}_{132}$ & $\begin{array}{l}\text { MC/stump } \\
\text { Proximal RMB medial wall } \\
\text { Proximal RMB medial wall }\end{array}$ & $\begin{array}{l}\text { CIS } \\
\text { CIS } \\
\text { SD }\end{array}$ & $\begin{array}{l}+ \\
+ \\
+\end{array}$ & $\begin{array}{l}\text { Mutant } \\
\text { Mutant } \\
\text { Mutant }\end{array}$ & $\begin{array}{l}\text { N/A } \\
\text { LoH } \\
\text { N/A }\end{array}$ \\
\hline $01 / 2009$ & $\mathrm{M}_{137}$ & $\begin{array}{l}\text { RMB } \\
\text { LMB stump }\end{array}$ & $\begin{array}{l}\text { CIS } \\
\text { CIS }\end{array}$ & $\begin{array}{l}+ \\
+\end{array}$ & $\begin{array}{l}\text { Mutant } \\
\text { Mutant }\end{array}$ & $\begin{array}{l}\mathrm{N} / \mathrm{A} \\
\mathrm{LoH}\end{array}$ \\
\hline $07 / 2009$ & $\mathrm{M}_{143}$ & $\begin{array}{l}\text { Lateral wall of orifice to RMB } \\
\text { Posterior wall proximal RMB } \\
\text { Left pneumonectomy stump }\end{array}$ & $\begin{array}{l}\text { CIS } \\
\text { CIS } \\
\text { CIS }\end{array}$ & $\begin{array}{l}+ \\
+ \\
+\end{array}$ & $\begin{array}{l}\text { Mutant } \\
\text { Mutant } \\
\text { Mutant }\end{array}$ & $\begin{array}{l}\text { LoH } \\
\text { LoH } \\
\text { LoH }\end{array}$ \\
\hline $11 / 2010$ & $\mathrm{M}_{159}$ & $\begin{array}{l}\text { RMB } \\
\text { RMB } \\
\text { MC } \\
\text { MC } \\
\text { MC (control) } \\
\text { RML (control) }\end{array}$ & $\begin{array}{l}\text { MiD } \\
\text { Metaplasia } \\
\text { CIS } \\
\text { MiD } \\
\text { NAD } \\
\text { NAD }\end{array}$ & $\begin{array}{l}- \\
- \\
+ \\
- \\
- \\
-\end{array}$ & $\begin{array}{l}\text { Wildtype } \\
\text { Wildtype } \\
\text { Mutant } \\
\text { Wildtype } \\
\text { Wildtype } \\
\text { Wildtype }\end{array}$ & $\begin{array}{l}\text { RoH } \\
\text { RoH } \\
\text { LoH } \\
\text { RoH } \\
\text { RoH } \\
\text { RoH }\end{array}$ \\
\hline $05 / 2011$ & $\mathrm{M}_{165}$ & RML & CIS & + & Mutant & $\mathrm{N} / \mathrm{A}$ \\
\hline $03 / 2012$ & $\mathrm{M}_{175}$ & $\begin{array}{l}\text { RML } \\
\text { RLL }\end{array}$ & $\begin{array}{l}\text { CIS } \\
\text { CIS }\end{array}$ & $\begin{array}{l}+ \\
+\end{array}$ & $\begin{array}{l}\text { Mutant } \\
\text { Mutant }\end{array}$ & $\begin{array}{l}N / A \\
N / A\end{array}$ \\
\hline $08 / 2012$ & $\mathrm{M}_{180}$ & Posterior wall of RMB & $\mathrm{SqCC}$ & + & Mutant & $\mathrm{N} / \mathrm{A}$ \\
\hline
\end{tabular}

Month refers to post-lobectomy

${ }^{*} A t M_{38}$, two distinct areas of the MC were biopsied, providing two AFB and histology normal samples.

†At $M_{70}$, two distinct AFB detected and histology-confirmed SD samples from the LLL orifice were analysed and found to carry the c.880delG. In total, 46 samples from 19 spatially distinct areas were analysed over a period of 12 years $\left(\mathrm{M}_{38}-\mathrm{M}_{180}\right)$.

AFB, auto-fluorescence bronchoscopy; CIS, carcinoma in situ; LLL, left lower lobe; LMB, left main bronchus; LoH, loss of heterozygosity; LUL, left upper lobe; MiD, mild dysplasia; MoD, moderate dysplasia; N/A, not analysed due to insufficient DNA lysate; NAD, no abnormality detected; RLL, right lower lobe; RMB, right main bronchus; RML, right middle lobe; RoH, retention of heterozygosity; RUL, right upper lobe; SD, severe dysplasia. 
two-allele peaks in tissue DNA after normalisation to the allele peak heights from constitutional DNA. A change of at least twofold in the allelic ratio was considered as $\mathrm{LoH}$. Microsatellite primer details for the $\mathrm{LoH}$ analysis are provided in online supplementary table S3.

\section{RESULTS}

Patients were selected from the UCLH Early Lung Cancer Detection Program. Of the 113 patients in this cohort with preinvasive lesions, 61 had follow-up data for more than 12 months, and 10 of these had an AFB detected and histologically confirmed high-grade (SD or CIS) lesion in the trachea. Eight of these had at least one visible high-grade lesion in the distal bronchial tree with seven having documentation of distal lesions prior to the tracheal CIS lesion. One of these patients had no biopsies available for analysis, and two had no mutations detected in the screened genes. The remaining five patients had longitudinally collected specimens with a somatic TP53 mutation. Patient demographics, clinical presentation and circumstances leading to the detection of preinvasive lesions are summarised in table 1 . All reported CIS lesions were detected by abnormal autofluorescence and histological confirmation. The number of months after initial presentation is documented as $\mathrm{M}_{\mathrm{x}}$ (eg, month $12-\mathrm{M}_{12}$ ). Full details for each patient's specimens are summarised in tables 2 and 3. Samples ranged from patient 1 , who had 46 tissue samples analysed over a period of 12 years (2000-2012), to patient 4, who had three tissue samples analysed over 2 months.

\section{Clonally related preinvasive lesions appear over time and} are spatially distinct

Patient 1 underwent left upper lobectomy for SqCC (T1N0M0) in 1997 (tumour $1, \mathrm{M}_{0}$ ). He had occasional episodes of haemoptysis but AFB was normal including the lobectomy stump $\left(\mathrm{M}_{10}\right)$. At $\mathrm{M}_{34}$ after further haemoptysis, CIS was detected near the lobectomy stump and the patient entered the UCLH Early Lung Cancer Detection Program. Sequencing of this CIS lesion $\left(\mathrm{M}_{38}\right)$ revealed the presence of a TP53 p.E294fs*51 deletion (c.880delG, exon 8) (figure 1). At this time $\left(\mathrm{M}_{38}\right)$, there were no further AFB-detectable lesions and normal epithelium (to AFB and histological analysis) biopsied as control tissue from six separate areas (figure 1) was TP53 wildtype. The mutant clone remained at the resection margins at $M_{43}$ and $M_{47}$. At $M_{64}$, a new AFB-detected spatially separate SD lesion in the left main bronchus (LMB) was positive for the TP53 deletion. Three further spatially distinct lesions in the left bronchial tree were detected at $\mathrm{M}_{70}$ (both SD) and both harboured the identical mutant clone. Normal epithelium lay between each lesion (AFB-negative, histologically normal and TP53 wildtype) confirmed at $\mathrm{M}_{51}, \mathrm{M}_{70}, \mathrm{M}_{74}, \mathrm{M}_{80}$ and $\mathrm{M}_{84}$. The TP53 deletion remained in a subsequent biopsy from a resampled CIS lesion $\left(\mathrm{M}_{74}\right)$. The patient underwent a completion left pneumonectomy $\left(\mathrm{M}_{91}\right)$ after developing a further SqCC within the left lower lobe (LLL) (tumour 2), beyond the main airways detected by CT scan.

A new CIS lesion at the MC $\left(\mathrm{M}_{104}\right)$, detected a year later, contained the same TP53 deletion (after previously being normal and TP53 wildtype at $\mathrm{M}_{38}$ ). Adjacent, control

Table 3 Clonality assessment over time in patients 2, 3, 4 and 5

\begin{tabular}{|c|c|c|c|c|c|c|}
\hline Patient & Bronchoscopy date & $\begin{array}{l}\text { Time } \\
\text { post-lobectomy (months) }\end{array}$ & Biopsy site & Diagnosis & Mutated gene (exon) & Mutation identified \\
\hline \multirow[t]{8}{*}{2} & $07 / 2001$ & $\mathrm{M}_{30}$ & MC (control) & NAD & - & Wildtype \\
\hline & \multirow[t]{2}{*}{$08 / 2002$} & \multirow{2}{*}{$M_{43}$} & LUL & SD & TP53-7 & p.C242F; c.725G>T \\
\hline & & & LLL stump & SD & TP53-7 & p.C242F; c.725G >T \\
\hline & \multirow[t]{3}{*}{$12 / 2002$} & \multirow[t]{3}{*}{$\mathrm{M}_{47}$} & MC & MoD & TP53-7 & p.C242F; c.725G >T \\
\hline & & & MC & Metaplasia & - & Wildtype \\
\hline & & & LUL/lingula sub & CIS & TP53-7 & p.C242F; c.725G>T \\
\hline & $03 / 2003$ & $\mathrm{M}_{50}$ & RLL segmentectomy & CA & KRAS & p.E88*; c.262G>T \\
\hline & $02 / 2006$ & $M_{85}$ & Trachea & CA & TP53-7 & p.C242F; c.725G >T \\
\hline \multirow[t]{6}{*}{3} & $05 / 2003$ & $M_{3}$ & MC (control) & NAD & - & Wildtype \\
\hline & $10 / 2003$ & $M_{8}$ & LUL stump & SD & TP53-5 & p.V173L; c.517G>T \\
\hline & $08 / 2005$ & $\mathrm{M}_{30}$ & Left pneumonectomy stump & $\mathrm{SD} / \mathrm{CIS}$ & & p.V173L; c.517G >T \\
\hline & $03 / 2006$ & $M_{37}$ & Trachea & CIS & & p.V173L; c.517G>T \\
\hline & \multirow[t]{2}{*}{$08 / 2006$} & \multirow[t]{2}{*}{$\mathrm{M}_{42}$} & Left pneumonectomy stump & $\mathrm{SqCC}$ & & p.V173L; c.517G>T \\
\hline & & & Lower trachea & $\mathrm{SqCC}$ & & p.V173L; c.517G>T \\
\hline \multirow[t]{5}{*}{4} & \multirow[t]{2}{*}{$07 / 2009$} & \multirow[t]{2}{*}{$M_{9}$} & \multirow[t]{2}{*}{ Proximal RMB } & \multirow[t]{2}{*}{ CIS } & \multirow[t]{2}{*}{ TP53-5 } & p.V173L; c.517G>T \\
\hline & & & & & & p.V157F; c.469G>T \\
\hline & \multirow[t]{3}{*}{$09 / 2009$} & \multirow[t]{3}{*}{$M_{11}$} & \multirow[t]{2}{*}{ RUL stump } & \multirow[t]{2}{*}{$\mathrm{SqCC}$} & \multirow[t]{3}{*}{ TP53-5 } & p.V173L; c.517G>T \\
\hline & & & & & & p.V157F; c.469G>T \\
\hline & & & Posterior wall lower trachea & $\mathrm{SqCC}$ & & p.V173L; c.517G >T \\
\hline \multirow[t]{11}{*}{5} & \multirow[t]{3}{*}{$06 / 2004$} & \multirow[t]{3}{*}{$M_{50}$} & LLL (control) & NAD & \multirow{5}{*}{$\begin{array}{l}- \\
- \\
\text { TP53-7 }\end{array}$} & Wildtype \\
\hline & & & LUL (control) & NAD & & Wildtype \\
\hline & & & Right lobectomy stump & MoD/SD & & p.C242R; c.724T>C \\
\hline & \multirow[t]{2}{*}{$11 / 2004$} & \multirow[t]{2}{*}{$M_{55}$} & \multirow[t]{2}{*}{ Right lobectomy stump } & \multirow[t]{2}{*}{ SD } & & p.C242R; c.724T>C \\
\hline & & & & & & p.G244D; c.731G>A \\
\hline & \multirow[t]{4}{*}{$04 / 2005$} & \multirow[t]{4}{*}{$M_{60}$} & \multirow[t]{2}{*}{ RIB } & CIS/Inv. & & p.C242R; c.724T>C \\
\hline & & & & & & p.G244D; c.731G>A \\
\hline & & & Lower trachea & CIS & & p.C242R; c.724T>C \\
\hline & & & & & & p.G244D; c.731G>A \\
\hline & $10 / 2005$ & $M_{66}$ & RMB polyp & SD & & p.C242R; c.724T>C \\
\hline & & & & & & p.G244D; c.731G>A \\
\hline
\end{tabular}



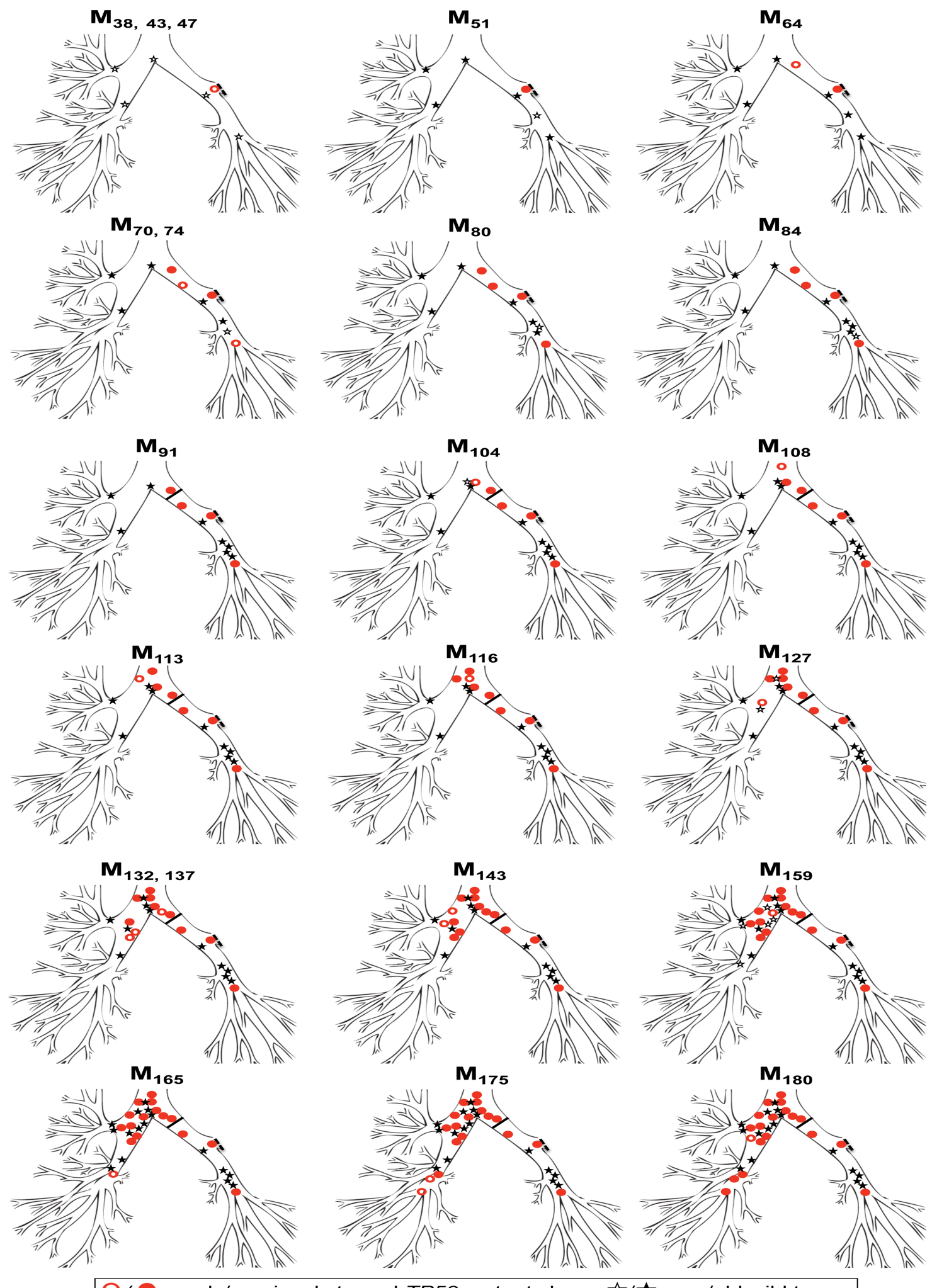

O/O newly/previously traced TP53 mutant clone $i \leqslant / \star$ new/old wild type

Figure 1 Spread of the TP53 p.E294fs 51 mutant clone (exon 8) over time in patient 1 . The mutant clone (red circle/filled red circle) was first detected at $\mathrm{M}_{38}$ in the left upper lobe (LUL) stump and spread over 142 months $\left(\mathrm{M}_{38}-\mathrm{M}_{180}\right)$ in a distal-to-proximal direction towards the $\mathrm{MC}$ and trachea and then over into the right lung. Control biopsies from autofluorescence bronchoscopy-negative areas confirmed histologically normal and genetically wildtype intervening epithelium (shown as black star or filled black star). The part of the lung surgically removed by lobectomy (dashed black line, LUL stump) is not shown. Completion pneumonectomy $\left(M_{91}\right)$ is depicted as a solid black line.

epithelium (AFB-negative, histologically normal) remained wildtype. Three subsequent bronchoscopies at $\mathrm{M}_{108}, \mathrm{M}_{113}$ and $\mathrm{M}_{116}$ detected new and spatially distinct CIS lesions in the lower trachea. All sites tested positive for the deletion, confirming a proximal spread of the mutant clone. At $\mathrm{M}_{127}$, the deletion was detected for the first time within the right main 
bronchus (RMB). Surrounding normal biopsies obtained at the same time were again wildtype. At $\mathrm{M}_{132}, \mathrm{M}_{137}, \mathrm{M}_{143}, \mathrm{M}_{165}$ and $\mathrm{M}_{175}$, autofluorescence demonstrated further spatially distinct lesions of CIS and SD in the right lung and all contained the identical TP53 deletion as detailed in table 2. Control biopsies from AFB normal sites showing normal or metaplastic areas of the right bronchial tree between AFB abnormal sites were TP53 wildtype.

Importantly, a CIS specimen obtained at $\mathrm{M}_{159}$ from a resampled site in the MC was still found to carry the deletion, but normal and mild dysplastic epithelium laser captured from either side of the MC CIS lesion was again TP53 wildtype. The TP53 mutation was finally traced in an invasive SqCC specimen (tumour 3) from the posterior wall of the RMB at $\mathrm{M}_{180}$, almost 12 years after its first detection in the left upper lobe (LUL) stump $\left(\mathrm{M}_{38}\right)$.

Based on these findings, we propose that the TP53 p.E294fs*51 clone originated at the LUL either prior to or within the 38 months of the lobectomy and subsequently skipped towards the $\mathrm{MC}$ and trachea and then into the right lung, giving rise to spatially distinct and clonally related lesions (table 2, figure 1). DNA material from the original resected tumour (tumour $1, \mathrm{M}_{0}$ ) was not available. Further evidence of their clonal relationship is provided by microsatellite- $\mathrm{LoH}$ analysis of a marker close to TP53, which showed a consistent loss of the same allele in all CIS/ SD cases (table 2).

Of particular interest are the normal molecular findings of control biopsies taken in between lesions and the normal epithelium laser captured from the margins of lesions. Of the 46 biopsies analysed for TP53, 27 were CIS/SD (58.7\%) and 19 were normal (41.3\%). All CIS lesions were AFB-detected and found to harbour the TP53 deletion. In contrast, all AFB-negative normal biopsies analysed were TP53 wildtype, indicating a $100 \%$ correlation between AFB and mutational status.

After noting the distal-to-proximal spread of these lesions into the trachea, we went on to determine whether other patients with tracheal CIS lesions had the same chronology and clonal relationship.

\section{Tracheal CIS occurs after secondary spread from a distal clonally related preinvasive lesion}

In early $1999\left(\mathrm{M}_{0}\right)$, patient 2 underwent a left lower lobectomy for SqCC (tumour 1, T1N0M0). CIS at the LLL stump resection margin was detected, and he entered into the surveillance programme. Over the following 47 months, he developed three new preinvasive lesions, each containing an identical TP53 p. $\mathrm{C} 242 \mathrm{~F}$, c.725G $>\mathrm{T}$ mutation (exon 7) (figure 2). The mutant clone spread proximally from the LLL to LUL/lingula and towards the MC. At $\mathrm{M}_{50}$, a CT scan and biopsy revealed a T1N0M0 poorly differentiated SqCC beyond the bronchoscopically visible airway in the right lung. Molecular analysis of the resected cancer revealed the presence of a K-RAS p.E88*, c. $262 \mathrm{G}>\mathrm{T}$ mutation but no TP53 mutation, indicating that this was an unrelated cancer (tumour 2). The CIS lesions within the airway were static by AFB for three and a half years, but the TP53 mutant clone was subsequently detected in a new lesion at $\mathrm{M}_{85}$ in the trachea (figure 2). Histology showed an area of CIS with local invasion (tumour 3; table 3).

Patient 3 had a left upper lobectomy for SqCC (T1N0M0) in February $2003\left(\mathrm{M}_{0}\right)$ and has since been under surveillance for CIS at the resection margin. A TP53 p.V173L, c.517G $>$ T mutation was detected in a resection margin specimen at $\mathrm{M}_{8}$, while a normal sample taken from the main carina at $\mathrm{M}_{3}$ was wildtype. At $\mathrm{M}_{12}$, the patient underwent a left completion

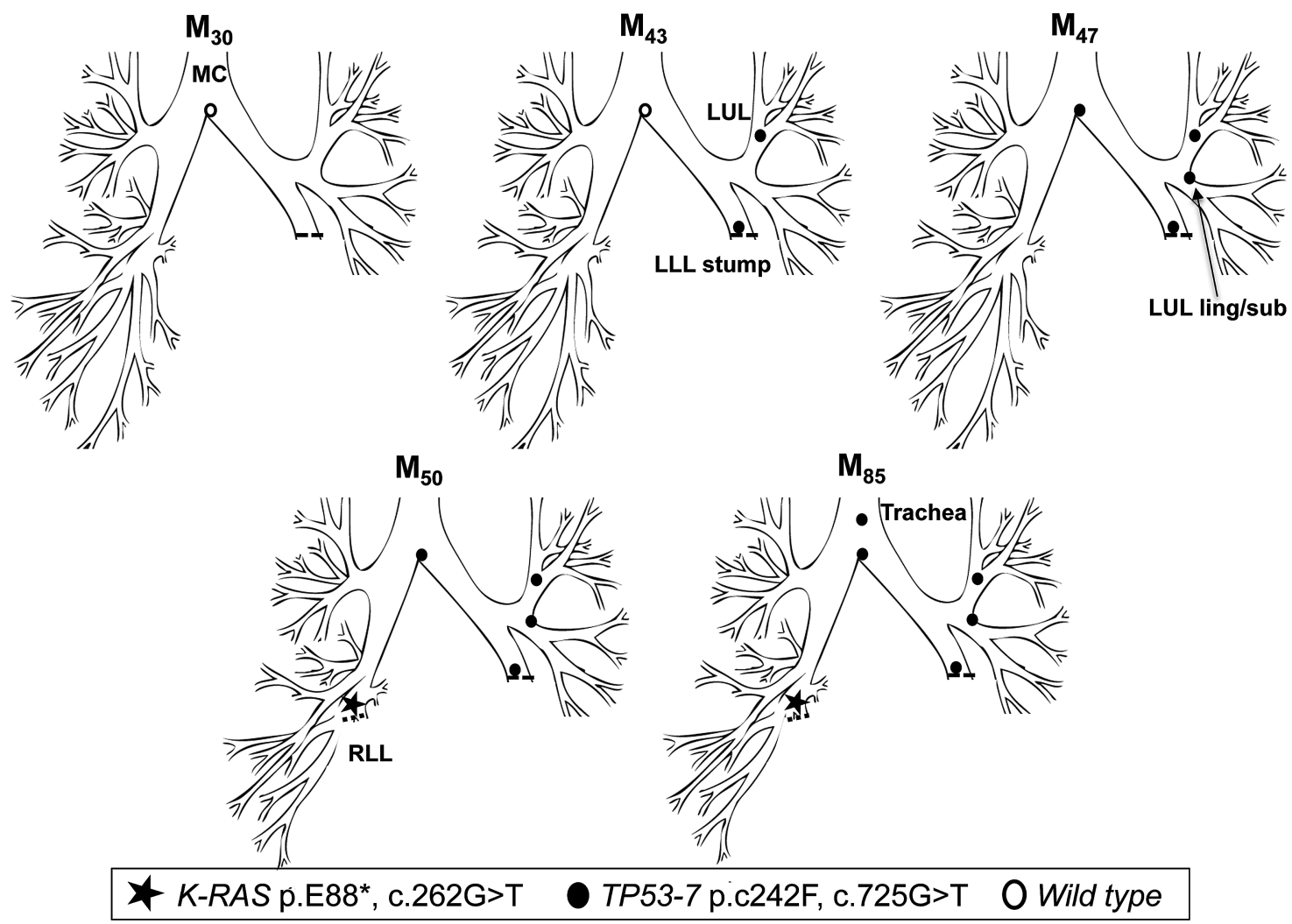

Figure 2 Tracing of the common mutant clone over time in the tracheobronchial tree of patient 2. Tracing the TP53 c.725G>T clone (exon 7) over 42 months from the left lower lobe stump $\left(\mathrm{M}_{43}\right)$ to the trachea $\left(\mathrm{M}_{85}\right)$. A second, unrelated tumour $(K-R A S \mathrm{c} .262 \mathrm{G}>\mathrm{T})$ was detected in the right lower lobe at $\mathrm{M}_{50}$. 

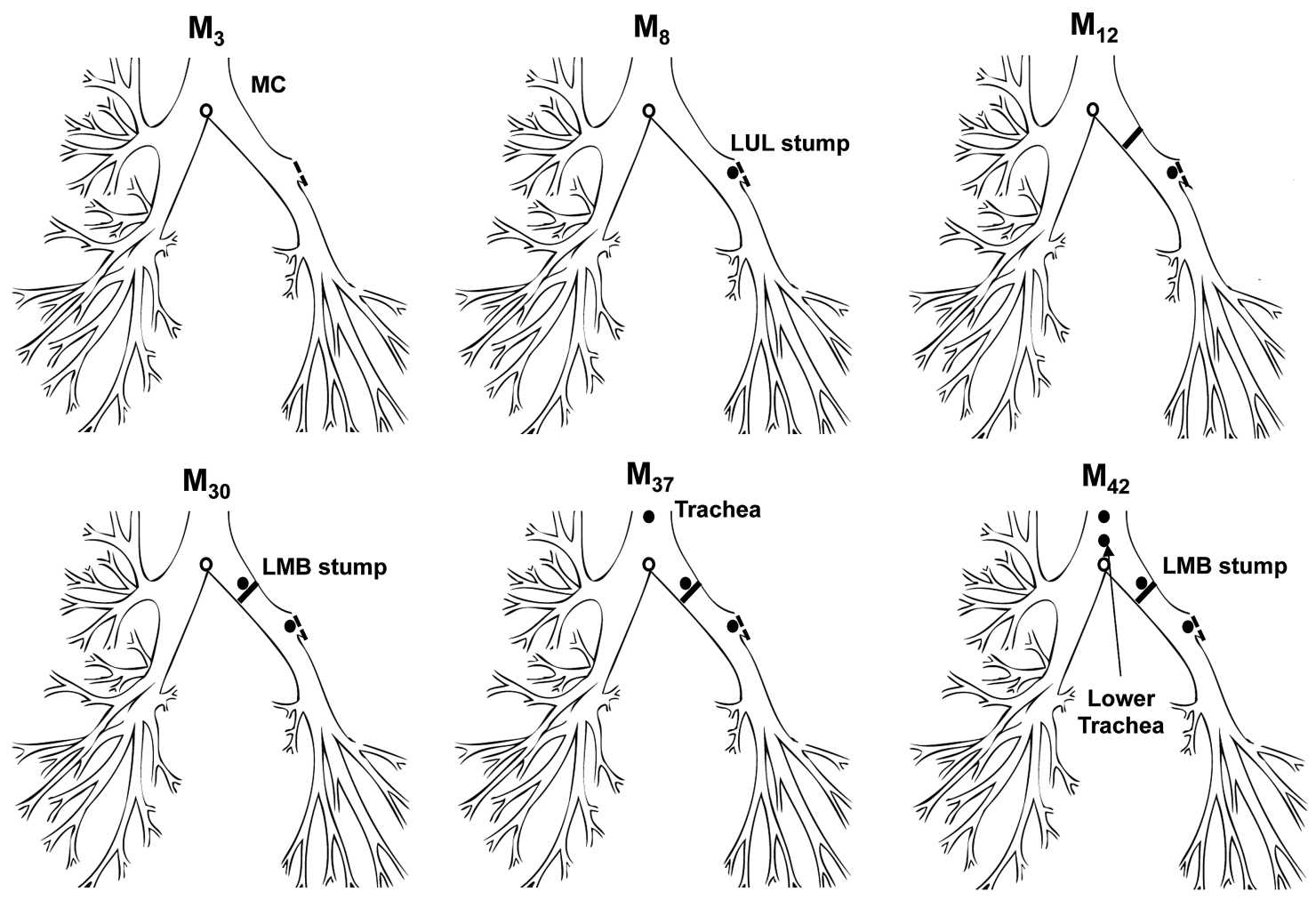

TP53-5 p.V173L, c.517G>T O Wild type

Figure 3 Tracing of the common mutant clone over time in the tracheobronchial tree of patient 3. Distal-to-proximal spread of the c.517G $>\mathrm{T}$ clone (TP53 exon 5) within 29 months from the left upper lobe stump $\left(M_{8}\right)$ to the trachea $\left(M_{37}\right)$. The clone must have arisen at the lower trachea earlier than $\mathrm{M}_{37}$.

pneumonectomy for clinical suspicion of invasion due to nodularity of the stump CIS lesion, but no evidence of microinvasive disease was found at pathology. Continued AFB surveillance later found the same mutation at the pneumonectomy stump $\left(\mathrm{M}_{30}\right)$, and at an AFB distinct lesion in the trachea $\left(\mathrm{M}_{37}\right)$. The patient eventually developed two microinvasive carcinomas at the pneumonectomy stump and trachea $\left(\mathrm{M}_{42}\right)$, both positive for the c.517G $>\mathrm{T}$ mutation (figure 3; table 3), for which he received photodynamic therapy at $\mathrm{M}_{44}$. We have shown previously the lesion at $\mathrm{M}_{8}$ and the pneumonectomy stump carcinoma at $\mathrm{M}_{42}$ to be monoclonal in origin based on a shared common $3 \mathrm{q}$ telomeric amplicon. ${ }^{21}$

Patient 4 underwent a right upper lobectomy in October $2008\left(\mathrm{M}_{0}\right)$ for poorly differentiated SqCC (T2N0). CIS at the resection margin was histologically confirmed, and the patient was referred for surveillance. A sample of this lesion showed two TP53 mutations: c.517G > T (p.V173L) and c.469G >T (p. $\mathrm{V} 157 \mathrm{~F}$ ) that matched a later developing CIS lesion obtained from the proximal RMB. The resection margin lesion progressed to invasive cancer at $\mathrm{M}_{11}$. Interestingly a second SqCC, detected at $\mathrm{M}_{11}$ within the posterior wall of the lower trachea, was found to harbour the c.517G $>\mathrm{T}$ clone but not the c. $469 \mathrm{G}>\mathrm{T}$, indicating the c. $517 \mathrm{G}>\mathrm{T}$ was the earlier mutation and cell migration from the original lesion occurred before the second mutation (figure 4; table 3).

Patient 5 underwent a right lower and middle lobectomy for SqCC (T1N0) in April $2000\left(\mathrm{M}_{0}\right)$. Residual CIS was reported at the resection margin. At referral to the centre $\left(M_{50}\right)$, AFB
Figure 4 Tracing of the common mutant clone over time in the tracheobronchial tree of patient 4. Detection of the $\mathrm{c} .517 \mathrm{G}>\mathrm{T}$ and c.469G $>$ T mutations (both TP53 exon 5) at the right upper lobe stump $\left(\mathrm{M}_{11}\right)$. Only one mutation was detected at the posterior wall of the trachea $\left(\mathrm{M}_{11}\right)$, suggesting this was the first mutation and these cells spread towards this site before the second mutation occurred.
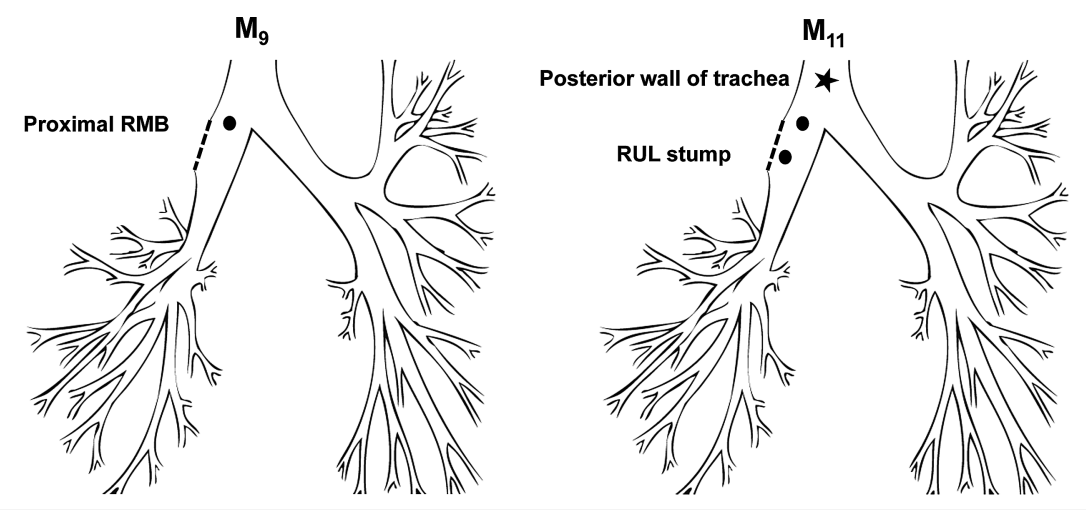

* TP53-5 p.V173L (c.517G>T) 
detected $\mathrm{MoD} / \mathrm{SD}$ at the lobectomy stump with genetic analysis revealing two TP53 mutations: p.C242R, c.724T $>C$ and p. G244D; c.731G >A (both in exon 7), with neither of the two mutant clones present in normal epithelium from the LUL and LLL. At $\mathrm{M}_{60}$, the same mutations were detected in two new lesions, one more proximally in the right intermediate bronchus (RIB, CIS with microinvasion) and a second in the lower trachea (CIS) (figure 5; table 3). At $\mathrm{M}_{66}$, a further lesion was detected in the RMB (SD) again harbouring both mutations.

Hence, all five patients developed clonally related but spatially distinct lesions over time spreading from distal-to-proximal airways.

\section{DISCUSSION}

We have used genetic analysis to define the natural history and clonal spread of preinvasive lesions identified by repeat AFB of the tracheobronchial tree in patients over periods of up to 12 years. In doing so, we have been able to document in situ the generation of multiple preinvasive lung cancer lesions giving new insight into field cancerisation of the lungs. Further, we show in all five patients with tracheal CIS that disease starts in the bronchial tree and moves proximally upwards into the trachea forming spatially distinct lesions.

The data presented here confirm that multifocal preinvasive lesions most frequently derive from a common clonal ancestor as suggested by the seminal paper by Franklin and colleagues ${ }^{15}$ rather than arising independently. ${ }^{14}$ Intriguingly, our AFB and genetic data show these lesions, while clonal are not contiguous, suggesting that cellular migration has occurred through the bronchial tree, with subsequent clonal expansion in a new environment. One remarkable patient demonstrates clonally related but physically distinct preinvasive lesions that moved in a distal-to-proximal spread from the left bronchial tree, up into the trachea, and down into the right bronchial tree over a period of 12 years. This raises significant biological questions regarding the mobility of airway epithelium and the evolutionary dynamics of the mutant clones. The distance travelled by spatially distinct clonal lesions over time gives us some idea of the rate of mutant cell migration. If we examine patient 1 , the mutant clone moves from the LUL entrance to the right lower lobe. This is $10.8 \mathrm{~cm}$, indicating a migration rate of $0.075 \mathrm{~cm} /$ month.
Our results support the concept of 'field cancerisation' in the lung but not by a mechanism previously postulated. Previous hypotheses include the 'field of injury' hypothesis (figure 6A), where all cells in a defined area are exposed to a damaging agent delivering the same insult to every cell. ${ }^{22}$ Alternatively, an individual cell clone has been postulated to expand relentlessly, possibly in response to injury, setting up a contiguous field of a mutant clone in which invasive disease can develop (figure 6B). ${ }^{23-25}$ Our results clearly mitigate against the latter hypothesis by demonstrating neighbouring, intervening epithelium between clonally related preinvasive lesions to be both normal in histology and wildtype for the genetic loci tested.

It is possible that we have missed thin snakes of CIS, migrating through the normal epithelium joining the lesions; however, we feel this is unlikely for a number of reasons. First, our PCR-detection method detects mutant TP53 at levels below 5\% when mixed with wildtype DNA. Furthermore, the longitudinal nature of our sampling would be expected to detect intervening abnormal cells over time. The LLL of patient 1 was tested wildtype at six different time points $\left(\mathrm{M}_{38}-\mathrm{M}_{84}\right.$; table 2$)$. Even if very few mutant CIS cells were initially present at the LLL at $\mathrm{M}_{38}$ that went undetected due to sensitivity issues, it might be expected to be able to find the mutation at a later time point after cell expansion. There has also never been any autofluorescent evidence of a snake of cells in any of the patients screened within our surveillance study.

The hypothesis that these lesions occur independently would mean that in our first patient the identical TP53 deletion occurred on at least 19 occasions, leading to pathologically identical but clonally separate lesions. The detected TP53 deletion does not lie within the mutational TP53 hotspot sites, ${ }^{26}$ and the statistical chances of the identical single deletion occurring in each of the samples sequenced are infinitesimally small. Our patient 1 data clearly show clonal expansion. The c.880delG mutation is reported just seven times in the total of 3128 simple TP53 sequence variants reported in the COSMIC mutation database. ${ }^{27}$ Assuming the mutation frequency of approximately 0.002 is representative of all neoplasia, the chance of two TP53 mutant cells both having the same c.880delG mutation is less than $5 \times 10^{-6}$. This is further supported by the observation that all preinvasive lesions also had the same pattern of allelic loss on $17 \mathrm{p}$, implying that the
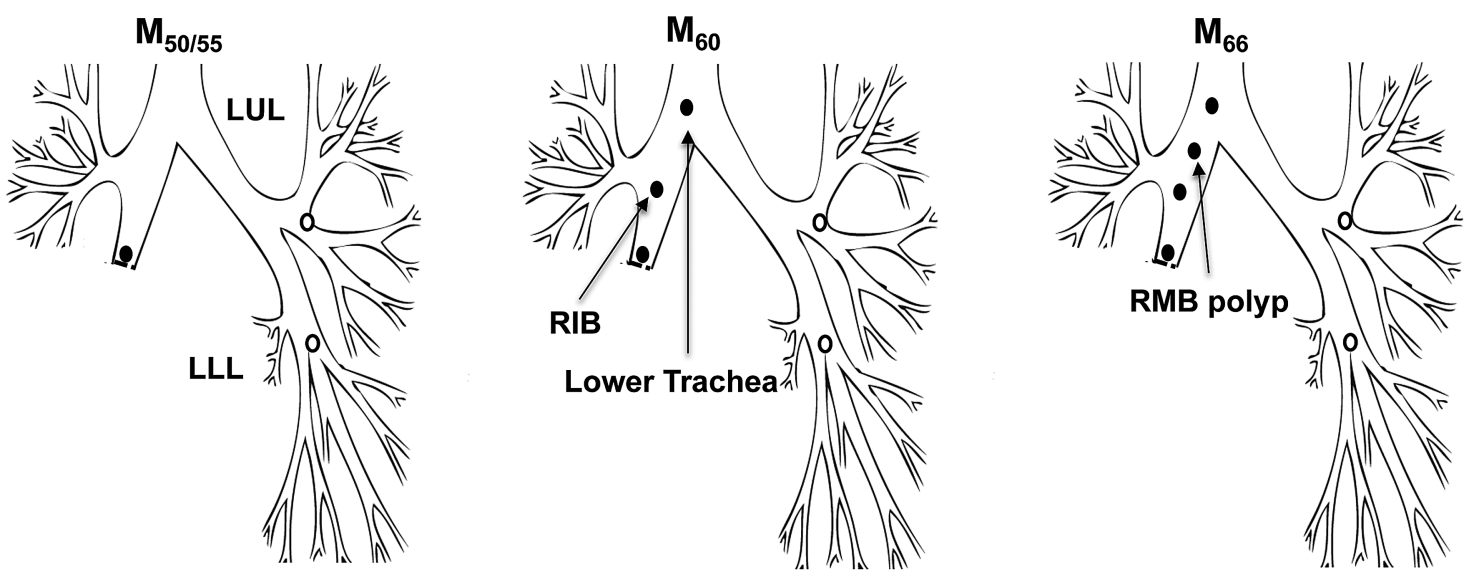

$$
\text { TP53-7 p.C242R (c.724T>C)/TP53-7 p.G244D (c.731G>A) O Wild type }
$$

Figure 5 Tracing of the common mutant clone over time in the tracheobronchial tree of patient 5. Simultaneous detection of the c.724T>C and c.731G >A clones (both TP53 exon 7) at the lobectomy stump 50 months postsurgery $\left(M_{50}\right)$ and distal-to-proximal spread towards the lower trachea. 
A

Aista

Damaging agent
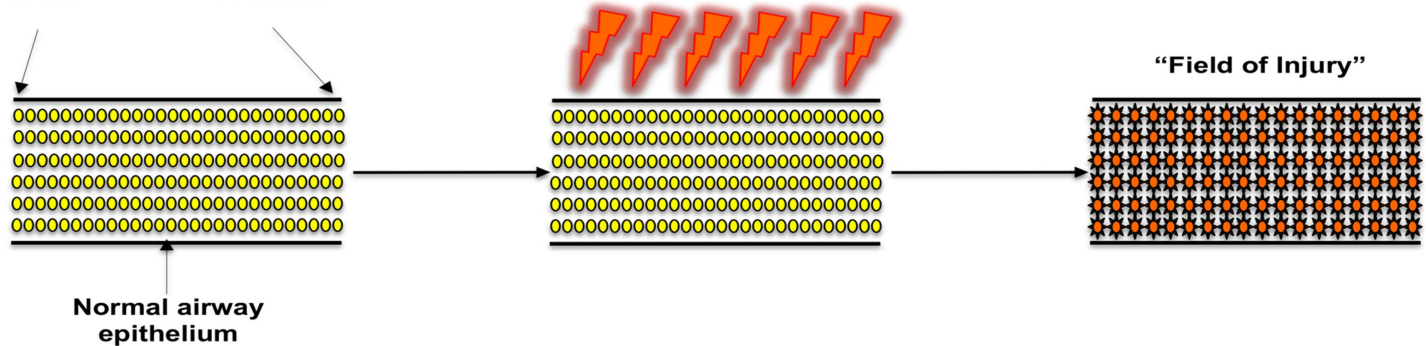

epithelium

B

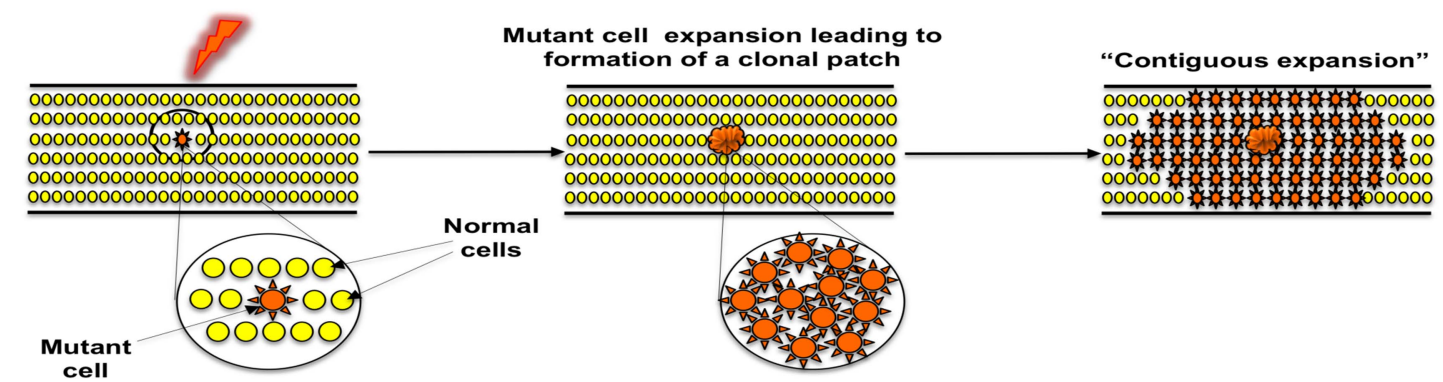

C

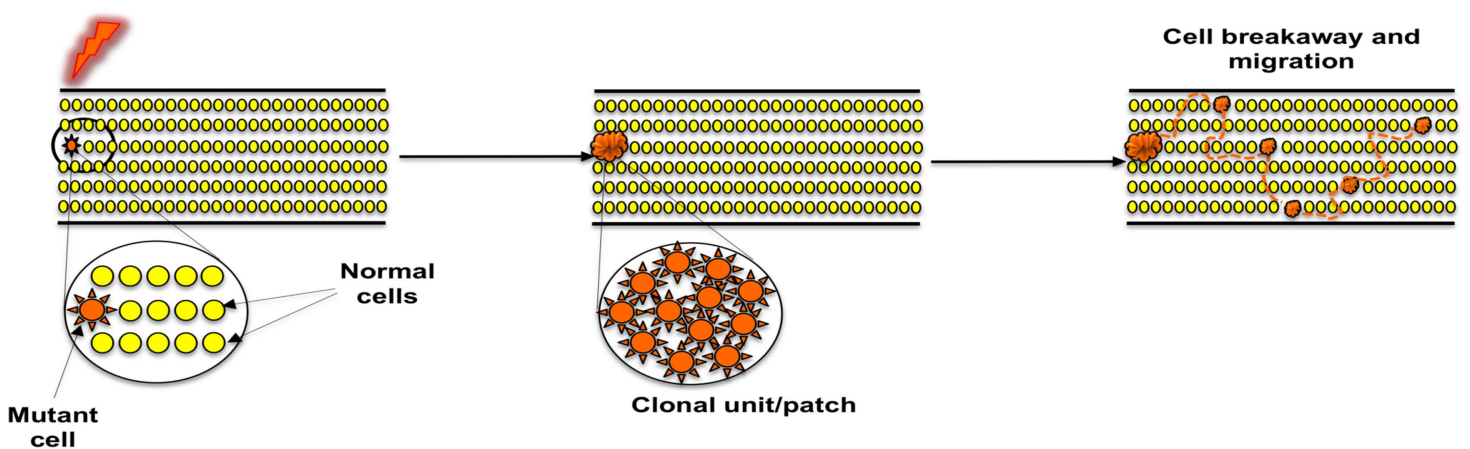

Figure 6 Proposed mechanisms of clonal spread of carcinoma in situ in the lung epithelium. (A) 'Field of injury'. Growth of clonally unrelated, multifocal lesions within a field predisposed to the same change after exposure to a common damaging agent. (B) 'Contiguous field'. Continuous expansion of a clone, giving rise to a patch of clonally related cells and formation of a progressively expanding contiguous field. (C) 'Cell breakaway and migration'. Following formation of a 'clonal unit' from an initial cell that acquired a proliferative advantage through acquisition of a mutation, a cell or group of cells breaks away from the unit and migrates via histologically normal and genetically wildtype epithelium in order to establish new lesions within a suitable niche.

c.880delG mutation was always present on the retained allele. Taken together, these findings suggest that it is highly unlikely for two unrelated cells to independently develop the same pattern of genetic defects, strongly indicating that these cells share a recent common clonal ancestor.

Our data therefore indicate subsequent preinvasive lesions occur as a result of individual cells or clusters of cells migrating and becoming established in a new environment where they experience a selective growth advantage (figure 6C). Interestingly, once on the bronchoscopy surveillance programme, all five patients quit smoking, indicating that the developments documented here are not related to new smoking damage. A final explanation for the apparent discontinuity of mutant cells could be 'healing' of the wildtype epithelium and concomitant fragmentation of the mutant cells, but this does not fit with the AFB findings.

These data are interesting when considering the details of clonal evolution in the preneoplastic lung. The extensive clonal expansion of TP53 mutant cells implies selection for these mutants, perhaps a consequence of dysregulated apoptotic and senescence machinery. However, the 'patchiness' of mutants suggests that the fitness may be slight, temporal or related to environmental factors, such that genetically wildtype cells are able to intervene between, and so presumably outcompete, the mutant cells. Our data suggest that the evolutionary dynamics constrain the clonal expansion of TP53 mutants such that they are unable to repopulate the entire epithelium in a contiguous sheet.

We cannot determine in our studies the cell of origin of these lesions, although by their nature the lesions consist of keratin 14-expressing basal cells recently proposed to be progenitor cells of the upper airway. ${ }^{28}{ }^{29}$ Long lifespan, self-renewal and the ability to replicate for extended periods of time support the hypothesis of stem or progenitor cell-induced tumourigenesis.

Our study provides further evidence that longitudinally occurring preinvasive lesions are clonally related and shows for the first time 
that these lesions are actually spatially distinct. These data catalogue field cancerisation in the lung and suggest that the evolutionary dynamics restrict mutant clones to grow in spatially distinct lesions rather than repopulating the entire epithelium. In addition, we document for the first time that tracheal CIS frequently develops from a distal CIS lesion in the bronchial tree. Our findings, therefore, demonstrate that while individual premalignant lesions may appear stable, they are capable of intra-airway migration. Currently it is not possible to predict which lesions will spread or progress to invasive cancers. Further study of the lesions that progress to cancer compared with those that remain stable or regress may provide molecular targets for the design of novel therapeutic approaches. Currently there are no randomised studies describing the best approach of treating these lesions. Treatments, however, should be tissue sparing because further lesions are likely to occur. Importantly, post-treatment, surveillance with detailed autofluorescent examination over extended time periods must also be offered to patients in order to detect subsequent developing CIS lesions that had metastasised pretreatment.

\section{Author affiliations}

${ }^{1}$ Lungs for Living Research Centre, UCL Respiratory, University College London, London, UK

${ }^{2}$ Department of Respiratory Medicine, University of Thessaly School of Medicine, Larissa, Greece

${ }^{3}$ Department of Pathology, University College London, London, UK

${ }^{4}$ Department of Thoracic Medicine, University College London Hospital, London, UK

${ }^{5}$ Department of Biochemistry, University of Cambridge, Cambridge, UK

${ }^{6}$ Department of Asthma, Allergy and Respiratory Science, King's College London, London, UK

${ }^{7}$ Histopathology Laboratory, Cancer Research UK London Research Institute, London, UK

${ }^{8}$ Centre for Digestive Diseases, Barts and the London School of Medicine and Dentistry, Queen Mary University of London, London, UK

${ }^{9}$ Centre for Evolution and Cancer, UCSF Helen Diller Family Comprehensive Cancer Center, San Francisco, California, USA

Acknowledgements The authors would like to acknowledge the members of the Equipment Park at the Cancer Research UK London Research Institute, Drs Petros Syrris and Chrysoula Dalageorgou (UCL), for access to their sequencing equipment, Miss Tania Ventayol-Garcia-Lopez and Dr Shabuddin Khan for help with the LOH work and Pamela Rabbitts and Cathy Read for their foresight and efforts in tissue collection.

Contributors CPP, TK, SACMCD, TAG and SMJ conceived the experiments. CPP and TK performed the experiments. JMB, NN, SMJ and PJG contributed samples. BC helped with sample collection and storage. SEB was involved in sample fixation and sectioning. MF and AC performed the histological review. CPP, TAG and SMJ wrote the paper. VHT, AV, FMCC, SACMCD, TAG, AG and NAW helped edit the paper. All authors had final approval of the submitted and published version.

Competing interests TK is the recipient of a European Respiratory Society Fellowship (Number 677). AG is the recipient of a European Research Council Starting Investigator award. SMJ is a Wellcome Trust Senior Fellow in Clinical Science (WT091730MA) and is supported by the Rosetrees Trust, Roy Castle Lung Cancer Foundation and UCLH Charitable foundation. This work was partially undertaken at UCLH/UCL who received a proportion of funding from the Department of Health's NIHR Biomedical Research Centre's funding scheme (SMJ, NN) and the UCL ECMC.

Ethics approval This study was approved by the Local Regional Ethical Committee (01/0148) and carried out in accordance with the Declaration of Helsinki (2000) of the World Medical Association.

Provenance and peer review Not commissioned; externally peer reviewed.

Open Access This is an Open Access article distributed in accordance with the terms of the Creative Commons Attribution (CC BY 3.0) license, which permits others to distribute, remix, adapt and build upon this work, for commercial use, provided the original work is properly cited. See: http://creativecommons.org/licenses/ by/3.0/

\section{REFERENCES}

1 Auerbach 0 , Stout AP, Hammond EC, et al. Changes in bronchial epithelium in relation to cigarette smoking and in relation to lung cancer. $N$ Engl J Med $1961 ; 265: 253-67$.
2 George PJ, Banerjee AK, Read CA, et al. Surveillance for the detection of early lung cancer in patients with bronchial dysplasia. Thorax 2007;62:43-50.

3 Pairolero PC, Williams DE, Bergstralh EJ, et al. Postsurgical stage I bronchogenic carcinoma: morbid implications of recurrent disease. Ann Thorac Surg 1984;38:331-8.

4 Rubin H. Fields and field cancerization: the preneoplastic origins of cancer: asymptomatic hyperplastic fields are precursors of neoplasia, and their progression to tumors can be tracked by saturation density in culture. Bioessays 2011;33:224-31.

5 Graham TA, McDonald SA, Wright NA. Field cancerization in the Gl tract. Future Oncol 2011;7:981-93

6 Sidransky D, Frost P, Von Eschenbach A, et al. Clonal origin of bladder cancer. N Engl J Med 1992;326:737-40.

7 Leedham SJ, Graham TA, Oukrif D, et al. Clonality, founder mutations, and field cancerization in human ulcerative colitis-associated neoplasia. Gastroenterology 2009;136:542-50.e6

8 Zhang W, Hanks AN, Boucher K, et al. UVB-induced apoptosis drives clonal expansion during tumor development. Carcinogenesis 2005;26:249-57.

9 Försti A, Louhelainen J, Söderberg M, et al. Loss of heterozygosity in tumour-adjacent normal tissue of breast and bladder cancer. Eur J Cancer 2001:37:1372-80.

10 McDonald SAC, Greaves LC, Gutierrez-Gonzalez L, et al. Mechanisms of field cancerization in the human stomach: the expansion and spread of mutated gastric stem cells. Gastroenterology 2008;134:500-10.

11 Maley CC, Galipeau PC, Li X, et al. Selectively advantageous mutations and hitchhikers in neoplasms: 16 lesions are selected in Barrett's esophagus. Cancer Res 2004;64:3414-27.

12 Mehra R, Tomlins SA, Yu J, et al. Characterization of TMPRSS2-ETS gene aberrations in androgen-independent metastatic prostate cancer. Cancer Res 2008:68:3584-90.

13 Slaughter PD, Southwick HW, Smejkal W. "Field Cancerization" in oral stratified squamous epithelium: Clinical implications of multicentric origin. Cancer 1953;6:963-8.

14 Braakhuis BJM, Tabor MP, Kummer JA, et al. A Genetic explanation of Slaughter's concept of field cancerization: evidence and clinical implications. Cancer Res 2003:63:1727-30.

15 Franklin WA, Gazdar AF, Haney J, et al. Widely dispersed p53 mutation in respiratory epithelium. A novel mechanism for field carcinogenesis. J Clin Invest 1997:100:2133-7

16 Sundaresan V, Ganly P, Hasleton P, et al. p53 and chromosome 3 abnormalities, characteristic of malignant lung tumours, are detectable in preinvasive lesions of the bronchus. Oncogene 1992;7:1989-97.

17 Hung J, Kishimoto Y, Sugio K, et al. Allele-specific chromosome $3 p$ deletions occur at an early stage in the pathogenesis of lung carcinoma. JAMA 1995:273:558-63.

18 Wistuba II, Behrens C, Milchgrub S, et al. Sequential molecular abnormalities are involved in the multistage development of squamous cell lung carcinoma. Oncogene 1999; 18:643-50.

19 Lam S, Kennedy $\mathrm{T}$, Unger M, et al. Localization of bronchial intraepithelial neoplastic lesions by fluorescence bronchoscopy. Chest 1998;113:696-702.

20 Banerjee AK, Rabbitts PH, George JP. Preinvasive bronchial lesions: surveillance or intervention? Chest 2004;125:95S-6S

21 McCaughan F, Pipinikas CP, Janes SM, et al. Genomic evidence of preinvasive clonal expansion, dispersal and progression in bronchial dysplasia. J Pathol 2011:224:153-9.

22 Steiling K, Ryan J, Brody JS, et al. The field of tissue injury in the lung and airway. Cancer Prev Res (Phila) 2008;1:396-403.

23 Tabor MP, Brakenhoff RH, Ruijter-Schippers HJ, et al. Multiple head and neck tumors frequently originate from a single preneoplastic lesion. Am J Pathol 2002; 161:1051-60.

24 Simon R, Eltze E, Schäfer KL, et al. Cytogenetic analysis of multifocal bladder cance supports a monoclonal origin and intraepithelial spread of tumor cells. Cancer Res 2001;61:355-62.

25 Prevo LJ, Sanchez CA, Galipeau PC, et al. p53-mutant clones and field effects in Barrett's esophagus. Cancer Res 1999;59:4784-7.

26 Petitjean $A$, Mathe $E$, Kato $S$, et al. Impact of mutant p53 functional properties on TP53 mutation patterns and tumor phenotype: lessons from recent developments in the IARC TP53 database. Hum Mut 2007;28:622-9.

27 Forbes SA, Bhamra G, Bamford S, et al. The Catalogue of Somatic Mutations in Cancer (COSMIC). Curr Protoc Hum Genet 2008; Chapter 10:Unit 10.11.

28 Rock JR, Onaitis MW, Rawlins EL, et al. Basal cells as stem cells of the mouse trachea and human airway epithelium. Proc Natl Acad Sci USA 2009;106:12771-5

29 Teixeira VH, Nadarajan P, Graham TA, et al. Stochastic homeostasis in human airway epithelium is achieved by neutral competition of basal cell progenitors. eLife 2013;2:e00966 